\title{
Application of flying jet plasma torch in wastewater treatment
}

\author{
Original Wameath S. Abdul-Majeed ${ }^{1}$, Abdullatif Khan ${ }^{2}$, Ahmed Al-Harrasi ${ }^{2}$ \\ Article $\quad{ }^{\prime}$ Department of Chemical and Petrochemical Engineering, University of Nizwa, Oman \\ ${ }^{2}$ UON Chair of Oman's Medicinal Plants and Marine Natural Products, Oman
}

\section{Keywords:}

Bacterial growth, $\mathrm{BOD}_{5}$, plasma torch, wastewater.

\section{Corresponding Author:}

Wameath S. Abdul-Majeed, Department of Chemical and Petrochemical Engineering, University of Nizwa, Oman.

Email: wameath@yahoo.com.

\section{Abstract}

The technologies for wastewater treatment are well-established; however, the goals for sustainable environmental management require more efforts in finding new robust and efficient methods with improved eco-friendly and optimized cost. Non-thermal plasma is considered a promising method in this respect due to the high degree of controllability, reduced cost and lower environmental impacts. In the current study, we investigated the application of flying jet plasma torch in the treatment of wastewater samples collected from different parts of Nizwa Sewage Treatment Plant. The objective was to contemplate the performance of novel approach that may induce higher treatment efficiency at reduced cost. Upon using plasma treatment for several durations (15 minutes to 2 hours), the results exhibited by the bacterial growth curve suggest a significantly higher reduction in biological and chemical oxygen demands as well as the de-activation of the microbial activity for several hours. The current findings show this considerable worth and indicate the feasibility of using jet plasma for wastewater treatment applications. The proposed technique was shown competitive to traditional wastewater treatment techniques in terms of process time, efficiency and operational cost.

\section{INTRODUCTION}

Since few decades, non-thermal plasma (NTP) was applied as a unique tool in different applications such as analytical chemistry, health care, environmental remediation, and sterilization of air and water. The electron temperature in NTP typically ranges from $1-10 \mathrm{eV}$; while the hot gas exists in the room temperature, which suggests the friendly use of NTP in several applications ${ }^{[1]}$. These highly energetic electrons produce free radicals from parent molecules in multi-step physical and chemical processes, leading to high destructive ability ${ }^{[1-7]}$. In terms of treating wastewater, NTP has been utilized in several studies to degrade organic pollutants ${ }^{[8-15]}$, to inactivate algae ${ }^{[16]}$ and to reduce chromium $\mathrm{VI}^{[17-18]}$. Different categories of glow discharge plasmas were generated in abovementioned studies and utilized for treating wastewater such as direct glow discharge, diaphragm glow discharge and anodic and multi anode contact glow discharge electrolysis. The treatment mechanism was attributed to the role of glow discharge in dissociating the water molecule into free hydroxyl radical $\left(\mathrm{O}^{*} \mathrm{H}\right)$ and sometimes hydrogen radical $\left(\mathrm{H}^{*}\right)$, which may interact to form $\mathrm{H}_{2} \mathrm{O}_{2}, \mathrm{HO}_{2}$ and $\mathrm{H}_{2}$. Then, several combinations of $\mathrm{O}^{*} \mathrm{H}, \mathrm{H}^{*}, \mathrm{H}_{2} \mathrm{O}_{2}$ and $\mathrm{H}_{2}$ diffuse into the liquid and oxidizes the organic molecules, nonselectively, into $\mathrm{CO}_{2}^{[8,19-21]}$. Important observation among the reported glow discharge generation techniques is the associated dependence of the degradation efficiency on the operating parameters. For instance, an increase in the dissociation efficiency of the glow discharge was reported with an increase in the applied current. Wang et al. ${ }^{[22]}$ and Liu et $a l^{[23]}$ demonstrated that a first-order degradation rate of nitrobenzene and chlorobenzene, respectively, increased linearly with an increase of current; in which the concentration of $\mathrm{H}_{2} \mathrm{O}_{2}$ generation and removal rate of substrate increased subsequently. They denoted that the current is proportional to the depth of the anode immersed (about $100 \mathrm{~mA}$ per $1.2 \mathrm{~mm}$ ). On the other hand, the applied voltage was found to be a critical parameter in the operation of contact glow discharge electrolysis equipment. Values up to 500 volts were hardly exceeded as the platinum anode would melt ${ }^{[24]}$. The distance between the electrodes in the glow discharge electrolysis device and the deepness of the anode inside the aqueous surface were also found critical operating parameters, in which distances up to $20 \mathrm{~mm}$ and $2.5 \mathrm{~mm}$ depth were found the optimum $^{[11,10]}$, respectively. Voltage and current effects were discussed thoroughly in our previous work ${ }^{[25]}$, in 
which we reported a mechanism for organic contaminants degradation in wastewater based on the hydroxyl radicals attack on the organic molecules resulting in fragmentation of the double bond long chain molecules, forming single bond molecules or even dissociating the molecules into other forms. We found that the efficiency of treatment has increased relatively with increasing the applied power in addition to the treatment time. Practically and due to above limitations, the operation of abovementioned types of glow discharge devices for treating wastewater is encountered with difficulties. In our previous study ${ }^{[25]}$, we developed a technique to treat wastewater based on cascade dielectric barrier discharge (DBD) atomizer, in which treatment of digested sludge for 10 minutes resulted in considerable reduction in the number of viable bacterial cells. Although the massive treatment efficiency achieved, the developed technique was encountered with size limitation in which the liquid was passed through the plasma bulk. Hence, it was necessary to find alternative technique that may impart proper efficiency and be adopted for industrial scale. In this study, we examine a flying jet plasma torch (FJPT $)^{[7]}$ for treatment of different wastewater samples collected from Nizwa Sewage Treatment Plant. The FJPT was developed recently in our labs and used in this research aimed at assessing the principal concept and investigating the process parameters leading to optimal treatment efficiency at reduced operational cost. The samples were collected from different stages of Nizwa sewage treatment plant (primary clarification, aeration stage and sludge thickener). We aimed at exploring the FJPT treatment effect on various bacterial contents. The experiments were carried out during April and May 2017 at the labs of Nizwa University. To the best of authors' knowledge, our study is the first shown in literature in this respect.

\section{MATERIALS AND METHODS}

In this research, a developed DBD platform - flying jet plasma torch (FJPT) was used to treat wastewater samples for several durations. The full details of the DBD platform - FJPT were presented in our previous work ${ }^{[7]}$. Illustration image for the experimental setup is shown in Figure 1. The FJPT was powered by a DBD plasma power source (DIDRIV10), purchased from Information Unlimited/USA. The device is equipped with independent voltage control from zero to a maximum output of $40 \mathrm{kV}$, independent current control from 5\% to maximum output and independent frequency control from 20 to $70 \mathrm{kHz}$. Argon gas $(99.995 \%)$, purchased from Muscat Gases Co. (Oman), at a rate $100 \mathrm{ml} / \mathrm{min}$ was applied for flying jet plasma generation through Teflon flow meter type purchased from maxtec.

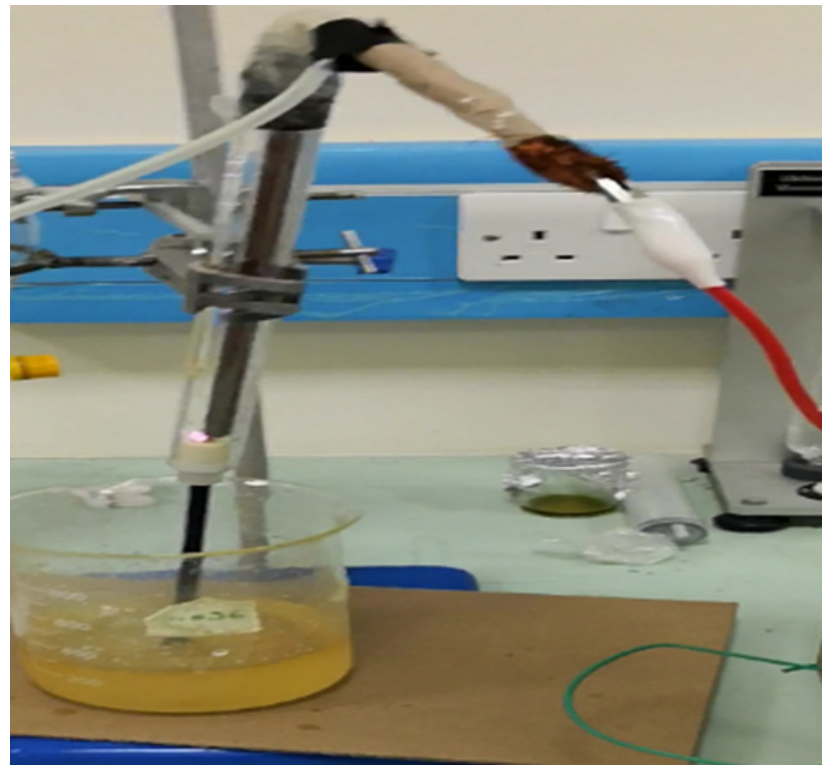

Fig. 1: Illustration image for the FJPT setup

Plasma jet was utilized in this research for the bacterial growth de-activation, in which samples of wastewater collected from Nizwa Sewage Treatment Plant were treated for different periods seeking for an optimal treatment efficiency. Sample 1 was supernatant collected from the primary clarification stage ; sample 2 was obtained from the bulk of the aeration stage, while sample 3 was brought from the sludge thickener. The tested samples were analyzed before and after being subjected to plasma treatment through measuring $\mathrm{pH}$, turbidity, biochemical oxygen demand and chemical oxygen demand. An acidity analyzer purchased from Elico (model LI614) was used to measure $\mathrm{pH}$. Nephelometric turbidity was measured through an analyzer (Elico CL52D, 0.01 resolution).

$\mathrm{BOD}_{5}$ was interpreted based on dissolved oxygen measurement ${ }^{[26]}$, while COD determination was based on the concept that oxidizable substances react with sulphuric acid- potassium dichromate solution in presence of silver sulphate as a catalyst. The FJPT treatment efficiency was elucidated through measuring the growth rate of the microorganisms after plasma treatment. No specific microorganisms were targeted in this study, while the focus was on counting the colonies in the examined agar plates. The agar plates were incubated for several nights at $37^{\circ} \mathrm{C}$ (human body temperature at which some of bodies bacteria will grow). The resulting colonies were adjusted with the appropriate dilution factors and counted, every few hours. The relative number of viable bacterial cells in the treated samples was defined by the length of the lag phase in a typical batch growth curve ${ }^{[25]}$. Four replicates 
measurements of each of the parameters were conducted and the averages and standard deviations were considered in the presented results.

\section{RESULTS AND DISCUSSION}

Treatments of three samples, mentioned above, were conducted by applying $2.5 \mathrm{kV}$ and $0.01 \mathrm{Amp}$ at around $30 \mathrm{kHz}$. These parameters were found the optimum in our previous work ${ }^{[27]}$ and hence applied in all experimental investigations in this research. The power consumption was assessed through producing the voltage charge diagram (Lissajous figure) in which the area enclosed by the Lissajous figure matches with the energy consumed per cycle of the applied voltage. Thus, the mean dissipated power in the plasma bulk is interpreted by the product of this energy and the applied frequency. In the DBD platform-FJPT, used in this study, the area of the voltage-charge diagram was found to be $0.98 \mathrm{~mJ}$. Hence, the power delivered to the DBD cell was estimated to be $29.4 \mathrm{~W}(=0.98 \mathrm{~mJ} \times 30 \mathrm{kHz})$.

The tested sample was put in an open flask at room temperature and subjected to the plasma jet effect $2 \mathrm{~cm}$ below the water surface. $300 \mathrm{~mL}, 500,700 \mathrm{ml}$ and 1000 $\mathrm{mL}$ of each sample were tested to conceive the efficiency of the FJPT treatment versus sample volume increase. It is noteworthy that the plasma jet was enforced in a local position inside the water. It means that the plasma effect was local in terms of fixed jet location and zero mechanical agitation. However, there was a slight mixing in the liquid bulk through the effluent gaseous stream from the jet. The treatment results (Tables 1-2) were assessed by measuring several parameters $\left(\mathrm{pH}\right.$, turbidity, $\left.\mathrm{BOD}_{5}, \mathrm{COD}\right)$. These parameters were normally adopted elsewhere ${ }^{[28]}$ when assessing the performance of such wastewater treatment scheme. It can be observed that a slight reduction on $\mathrm{pH}$ values $(<5 \%)$ occurred, in general, due to plasma treatment. This was more obvious for sample 3 results and could be attributed to the hydrogen radicals generated inside the plasma bulk. The general trend for all treated samples is the reduction of $\mathrm{pH}$ values with increasing treatment time. However, inconsistent increase in $\mathrm{pH}$ values was observed for some measured values of samples 1 and 2 for no obvious reason rather than the instrumental error.

Table 1: $\mathrm{pH}$ and nephelometric turbidity measurements, Sample volume $=500 \mathrm{~mL}$

\begin{tabular}{lcccccc}
\hline & \multicolumn{2}{c}{ Sample 1 } & \multicolumn{2}{c}{ Sample 2 } & \multicolumn{2}{c}{ Sample 3 } \\
\hline & $\mathrm{pH}$ & Turbidity, NTU & $\mathrm{pH}$ & Turbidity, NTU & $\mathrm{pH}$ & Turbidity, NTU \\
Before treatment & 8.16 & 2.16 & 7.89 & 4.5 & 7.62 & 778 \\
Treatment for 15 min & 8.13 & 2.13 & 7.81 & 4.35 & 7.35 & 768 \\
Treatment for 30 min & 8.16 & 2.13 & 7.86 & 4.5 & 7.33 & 546 \\
Treatment for 60 min & 8.10 & 1.9 & 7.87 & 3.98 & 7.20 & 409 \\
Treatment for 90 min & 8.14 & 1.65 & 7.82 & 3.67 & 7.20 & 460 \\
Treatment for 120 min & 8.06 & 1.64 & 7.67 & 3.6 & 7.19 & 417 \\
\hline
\end{tabular}

Table 2: $\mathrm{BOD}_{5}$ and COD measurements, Sample volume $=500 \mathrm{~mL}$

\begin{tabular}{|c|c|c|c|c|c|c|}
\hline & \multicolumn{2}{|c|}{ Sample 1} & \multicolumn{2}{|c|}{ Sample 2} & \multicolumn{2}{|c|}{ Sample 3} \\
\hline & $\begin{array}{l}\mathrm{BOD}_{5} \\
\mathrm{mg} / \mathrm{L}\end{array}$ & $\begin{array}{l}\mathrm{COD} \\
\mathrm{mg} / \mathrm{L}\end{array}$ & $\begin{array}{c}\mathrm{BOD}_{5} \\
\mathrm{mg} / \mathrm{L}\end{array}$ & $\begin{array}{l}\mathrm{COD} \\
\mathrm{mg} / \mathrm{L}\end{array}$ & $\begin{array}{c}\mathrm{BOD}_{5} \\
\mathrm{mg} / \mathrm{L}\end{array}$ & $\begin{array}{l}\mathrm{COD} \\
\mathrm{mg} / \mathrm{L}\end{array}$ \\
\hline Before treatment & 8.50 & 25 & 15.60 & 30 & 144 & 240 \\
\hline Treatment for $15 \mathrm{~min}$ & 5.32 & 20 & 10.93 & 26 & 127 & 231 \\
\hline Treatment for $30 \mathrm{~min}$ & 5.02 & 16 & 8.03 & 20 & 69 & 201 \\
\hline Treatment for $60 \mathrm{~min}$ & 3.30 & 14 & 5.03 & 17 & 58 & 178 \\
\hline Treatment for $90 \mathrm{~min}$ & 3.00 & 8 & 4.26 & 13 & 43 & 150 \\
\hline Treatment for $120 \mathrm{~min}$ & 1.90 & 6 & 4.09 & 9 & 40 & 139 \\
\hline
\end{tabular}


On the other hand, the turbidity measurements for the examined samples indicated obvious decline especially for sample $3(\approx 50 \%)$. This clearly indicates positive effect as the number of suspended solids has reduced ultimately. Looking at the $\mathrm{BOD}_{5}$ and $\mathrm{COD}$, measurements clearly demonstrate the treatment effectiveness, in which huge reductions occurred especially on sample 3 treated for 2 hours $\left(72 \%\right.$ reduction in $\mathrm{BOD}_{5}$ and $42 \%$ reduction in COD).

The efficiency of the jet plasma treatment was validated upon counting the number of the microorganism colonies per agar before and after treatment. It is worth noting that plasma treatment led to organism lyses and the lysed cells form irregular shapes compared with circular or cylindrical shape for the un-affected cells ${ }^{[25]}$. An illustrating image for lysed cells is shown in Figure 8. According to the literature, the number of microorganisms in wastewater sample was interpreted through different methodologies. Cai and Zhang ${ }^{[29]}$ applied 16S rRNA genes as a fingerprint to detect bacterial pathogens in domestic wastewater. They hit around 25000 green genes ; among them, 1600 were identified as pathogenic bacteria. Kwiatkowska and Zielin' ska $^{[30]}$ reported that Ascomycota is the most abundant phylum, constituting $6.3-7.4 \%$ of microorganisms, in domestic wastewater. Also, Wang et al. ${ }^{[31]}$ denoted that Sphingobacteriales, Anaerolineales, Rhodocyclales, Burkholderiales, Rhizobiales, Xanthomonadales, Verrucomicrobiales, Clostridiales, Planctomycetales and Myxococcales were found common in activated sludge from 14 sewage treatment plants and accounted for over $95 \%$ of all sequences.

As mentioned in the "Introduction", radicals play an important role in the microorganisms' treatment process. A high voltage electrical discharge in the gas phase above the water surface or in the water itself (i.e. electrohydraulic discharge) is able to produce many species such as molecular oxygen and hydrogen, hydrogen peroxide, hydroperoxyl, hydroxyl and other radicals. $\mathrm{OH}$ species were shown to be the most effective among these radicals ${ }^{[25]}$. OH radicals could result from a dissociative reaction such as the recombination of hydronium ion $\left(\mathrm{H}_{3} \mathrm{O}^{+}\right)$with electron in the plasma bulk.

Our results (Table 3 ) for $300 \mathrm{~mL}$ of sample 2 showed that the bacterial activity in the exponential phase represented by the growth of incubated samples after plasma treatment is around $61 \%$ (for 30 min treatment) and $55 \%$ (for 1 hour treatment) compared with the incubated sample with no treatment. Sample 2 was selected for this data demonstration as the resulted number of colonies was moderate and easier to count compared with higher colonies number in the activated sludge sample. After around $70 \mathrm{hrs}$ incubation, the number of colonies remains the same for few hours and then started to decrease where nutrients are depleted or toxic products accumulate; thereby cell growth rate slows and some cells may begin to die. The same effect was observed for samples 1 and 3 , which indicates that the jet plasma has played important role on the microorganisms deactivation.

Table 3: Bacterial growth data (Number of colonies counted per one agar plate). Sample 2, collected from the primary clarification stage, volume $=300 \mathrm{~mL}$

Number of colonies counted after incubation

Treatment status

(Exponential phase)

\begin{tabular}{lcccccc}
\cline { 2 - 4 } & $12 \mathrm{hrs}$ & $24 \mathrm{hrs}$ & $36 \mathrm{hrs}$ & $48 \mathrm{hrs}$ & $60 \mathrm{hrs}$ & $72 \mathrm{hrs}$ \\
No treatment & 22 & 54 & 64 & 74 & 82 & 88 \\
Treatment for 30 min & 8 & 19 & 28 & 41 & 49 & 43 \\
Treatment for 60 min & 4 & 14 & 23 & 37 & 43 & 48 \\
\hline
\end{tabular}

The number of colonies counted after FJPT treatment for three samples collected from primary clarification stage, aeration stage, and the sludge thickener in Nizwa STP were used to evaluate the efficiency of the applied treatment scheme. Figures 2-4 represent a comparison between the bacterial growths of incubated samples after plasma treatment for $700 \mathrm{~mL}$ tested volume. The results for all treated samples demonstrate that increasing the treatment duration resulted in more deactivation for the bacteria and hence treatment duration was identified as a key factor in this scheme. Increasing the treatment duration to 2 hours has resulted in $44 \%$ reduction in the colonies number of sample 3 and around the same for other samples compared with a sample treated for 15 minutes.

In the same respect, an optimization study was conducted to contemplate the effect of sample volume $(300,500,700$ and $1000 \mathrm{~mL}$, respectively) on the treatment efficiency at constant plasma density. Sample 3, collected from the sludge thickener, was selected as it is deemed richest of viable bacterial cells. Although smallest sample volume is logically more responsive to the plasma treatment, the results (Figures 5-7) demonstrated that an increase in the 
treated sample volume has revealed a limited effect on the treatment efficiency, which was more obvious in the case of FJPT treatment for 90 minutes (Figure 7). In general, the results (Figures 5-7) have shown that the treatment efficiency is mainly affected by the plasma exposure time. The sample volume effect was also noticeable up to such extent. However, longer exposure time (90 min) has resulted in depleting the effect of the sample volume and all growth curves were resulted in the same trend and level. As the exerted power was the same in all studied cases, the number of colonies counted for $300 \mathrm{~mL}$ sample was found slightly far from the results observed for other volumes.

A conclusive clue from this result denoted that a 90 minutes' treatment of one liter liquid volume (rich with viable microorganisms) via FJPT operated at $100 \mathrm{~mL} / \mathrm{min}$ Argon and powered by 30 watts $(2.5 \mathrm{kV}$ and $0.01 \mathrm{Amp}$ at around $30 \mathrm{kHz}$ ) is optimum to deactivate the viable bacterial cells for around 24 hours. Practical wise, this finding is challenging and competes with the results shown in the literature in terms of achieving considerable treatment efficiency at very low current consumption. Of course this will be reflected on limited increase in the liquid temperature upon subjecting to plasma treatment and consequently omitting the need for cooling in the liquid bulk. This has been confirmed by measuring the liquid temperature throughout the treatment durations, in which an increase of $7^{\circ} \mathrm{C}$ was observed in the worst case.

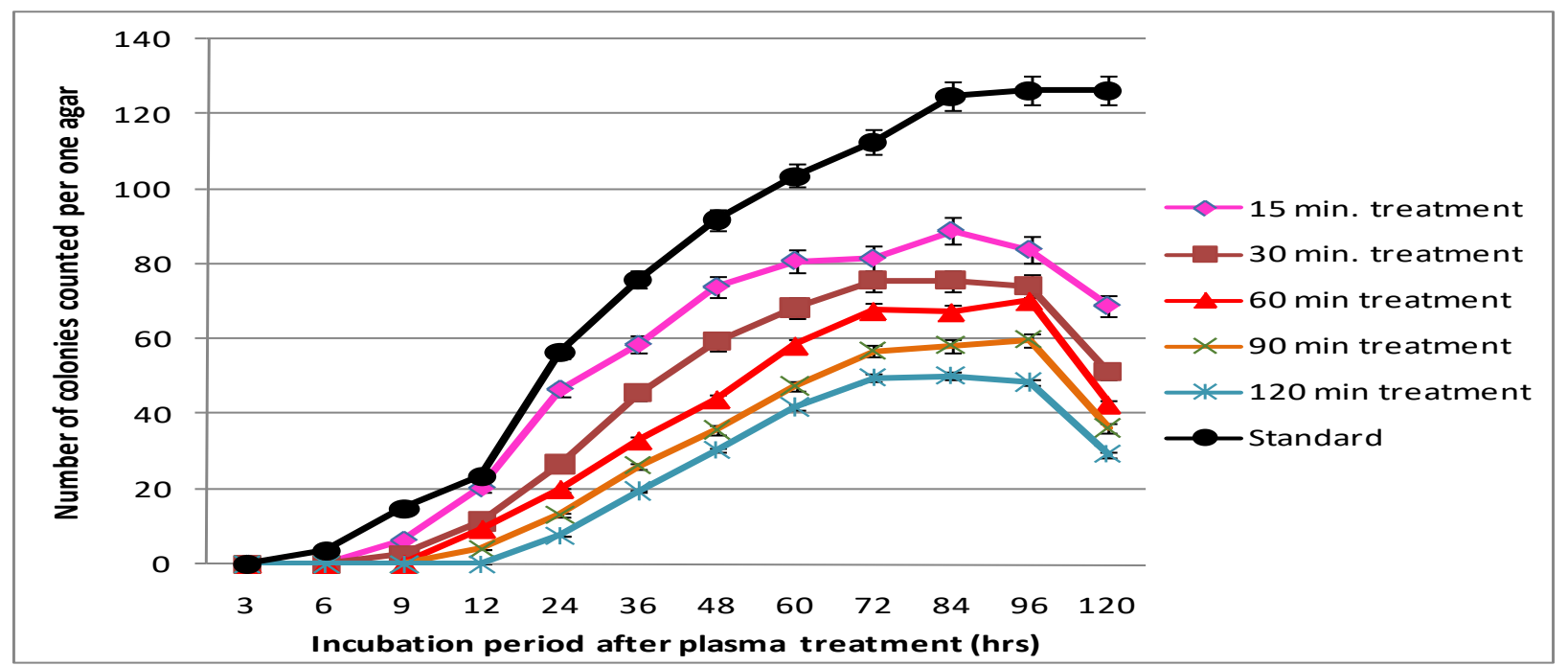

Fig. 2: Number of colonies counted after FJPT treatment for $700 \mathrm{~mL}$ of sample 1 collected from the primary clarification stage in Nizwa STP

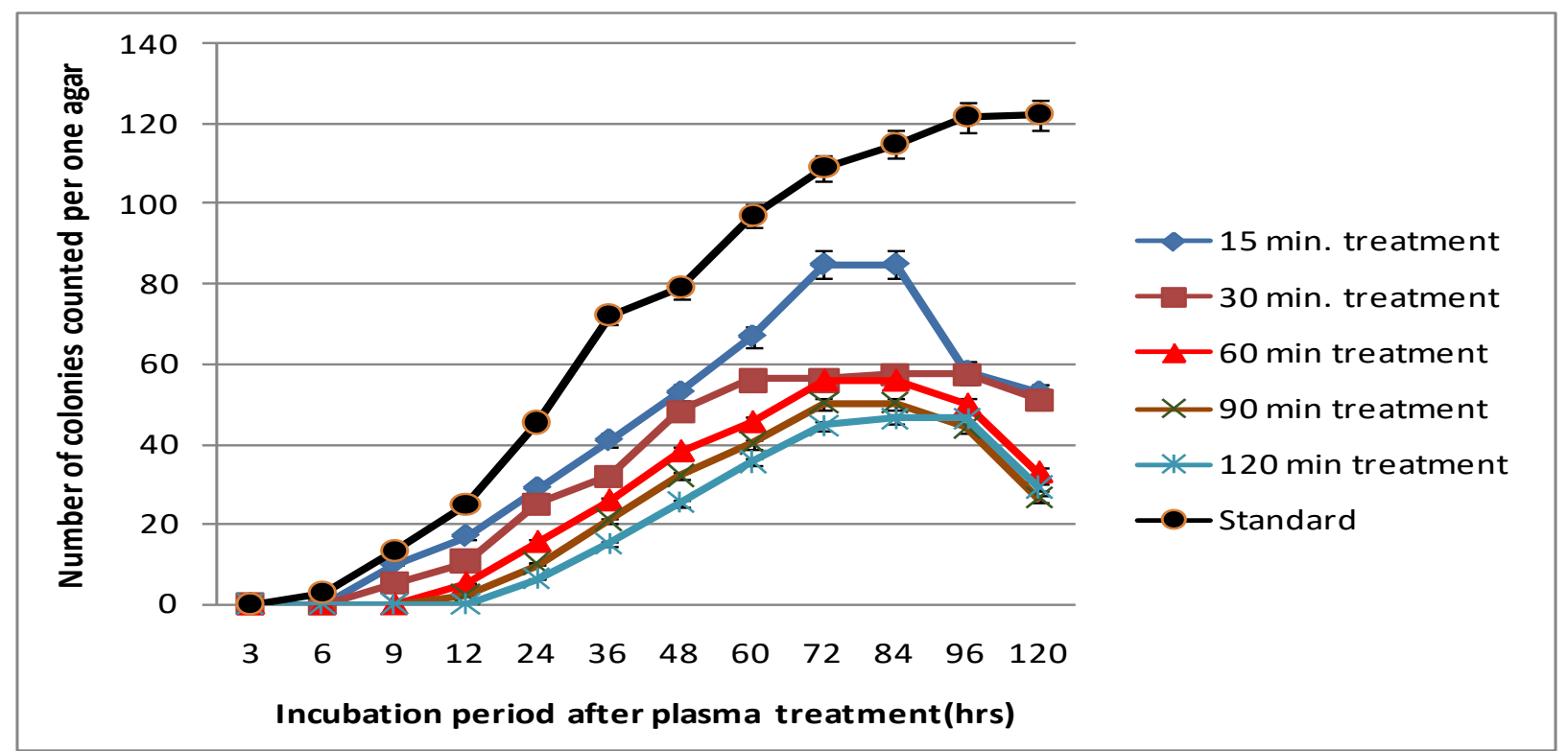

Fig. 3: Number of colonies counted after FJPT treatment for $700 \mathrm{~mL}$ of sample 2 collected from the aeration stage in Nizwa STP 


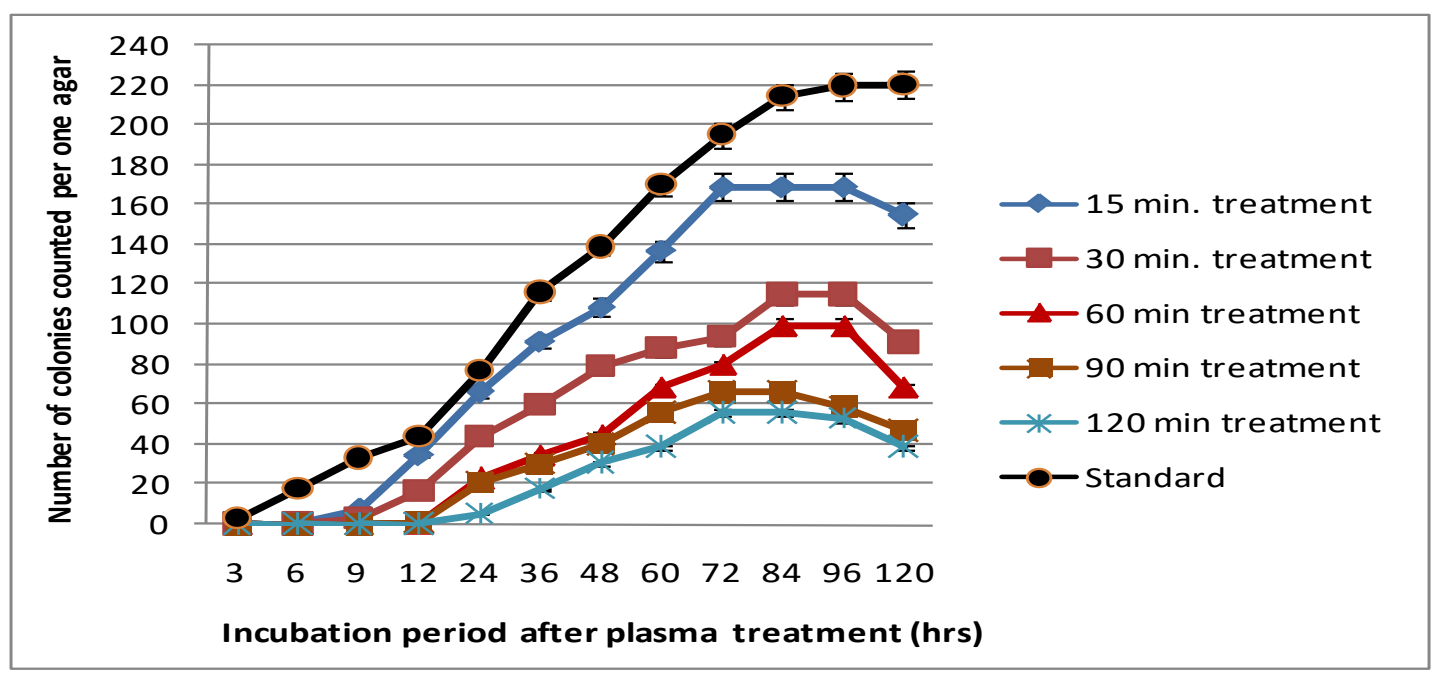

Fig. 4: Number of colonies counted after FJPT treatment for $700 \mathrm{~mL}$ of sample 3 collected from the sludge thickener in Nizwa STP.

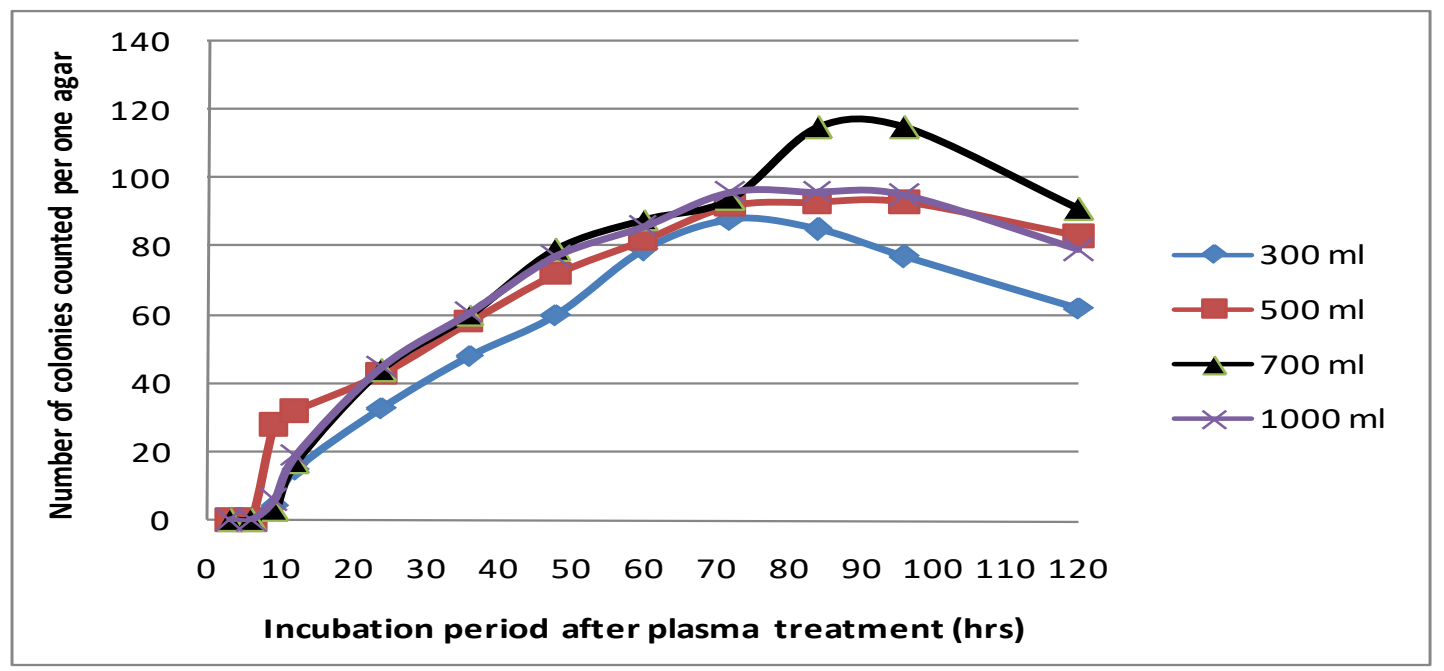

Fig. 5: Number of colonies counted after 30 minutes FJPT treatment for different volumes of sample 3.

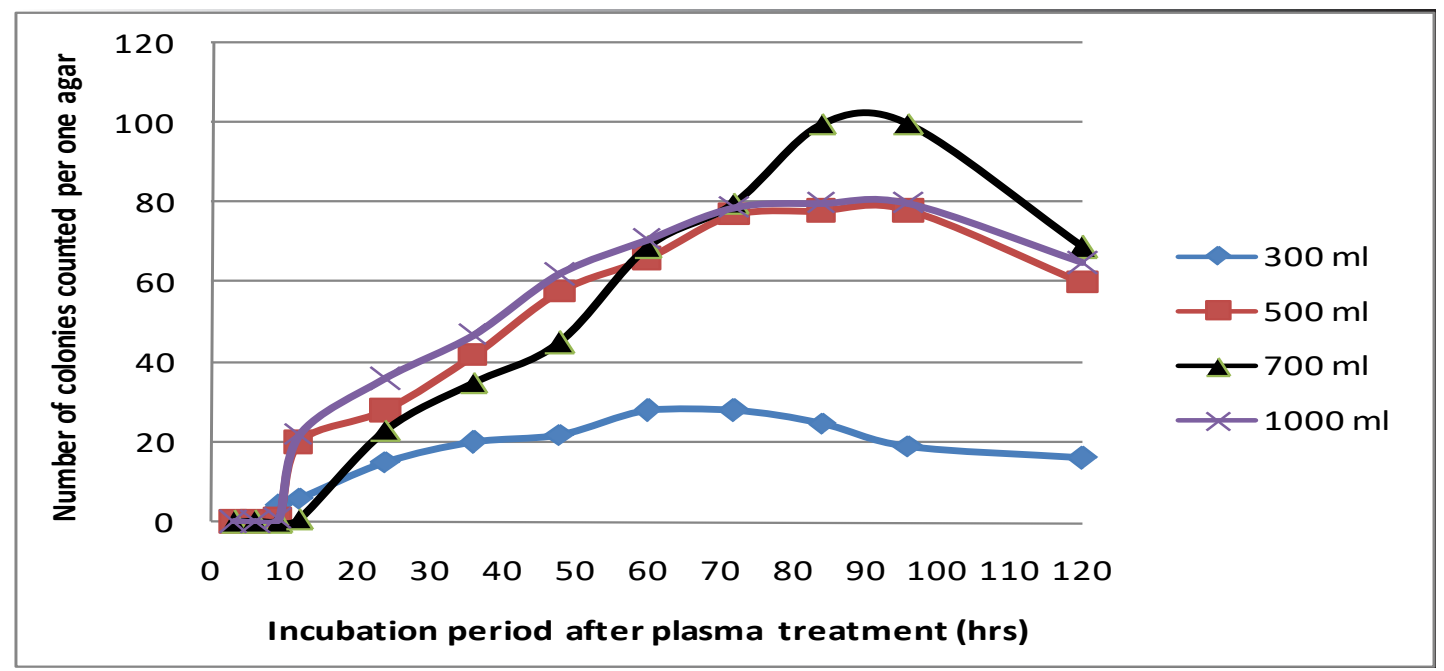

Fig. 6: Number of colonies counted after 60 minutes FJPT treatment for different volumes of sample 3. 


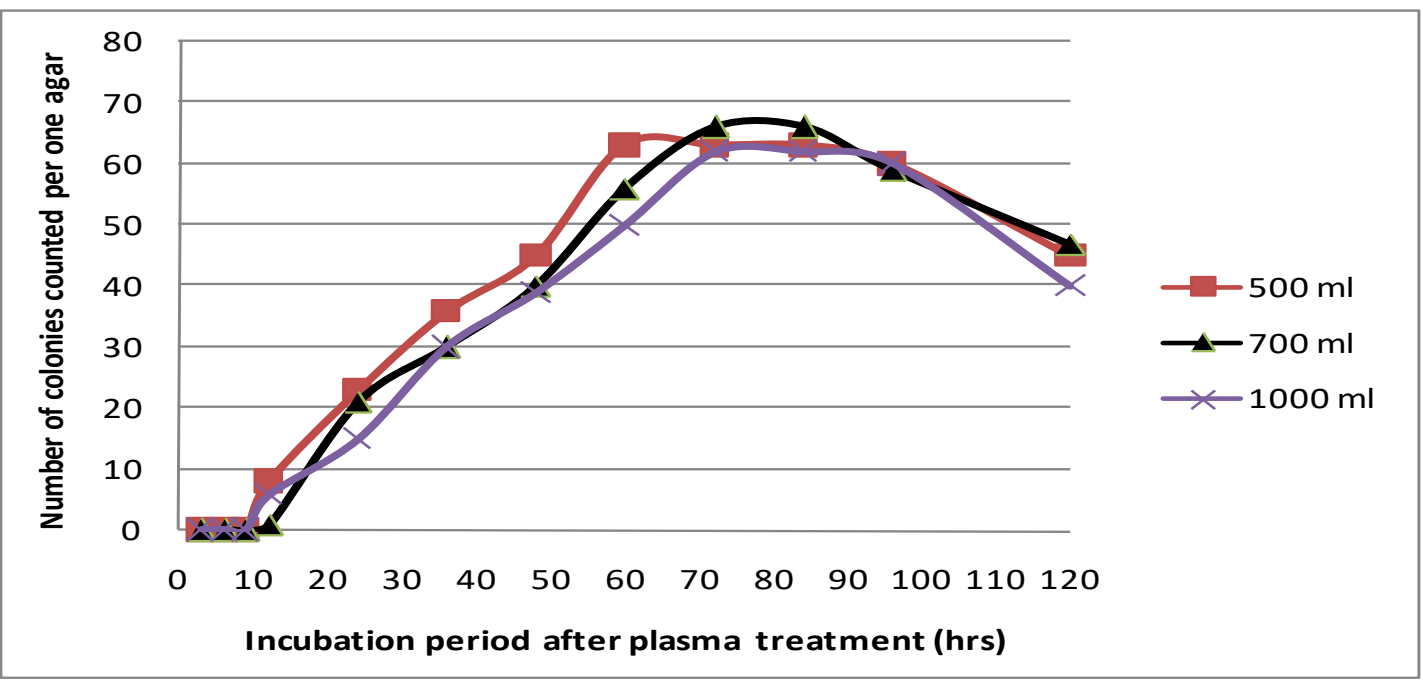

Fig. 7: Number of colonies counted after 90 minutes FJPT treatment for different volumes of sample 3.

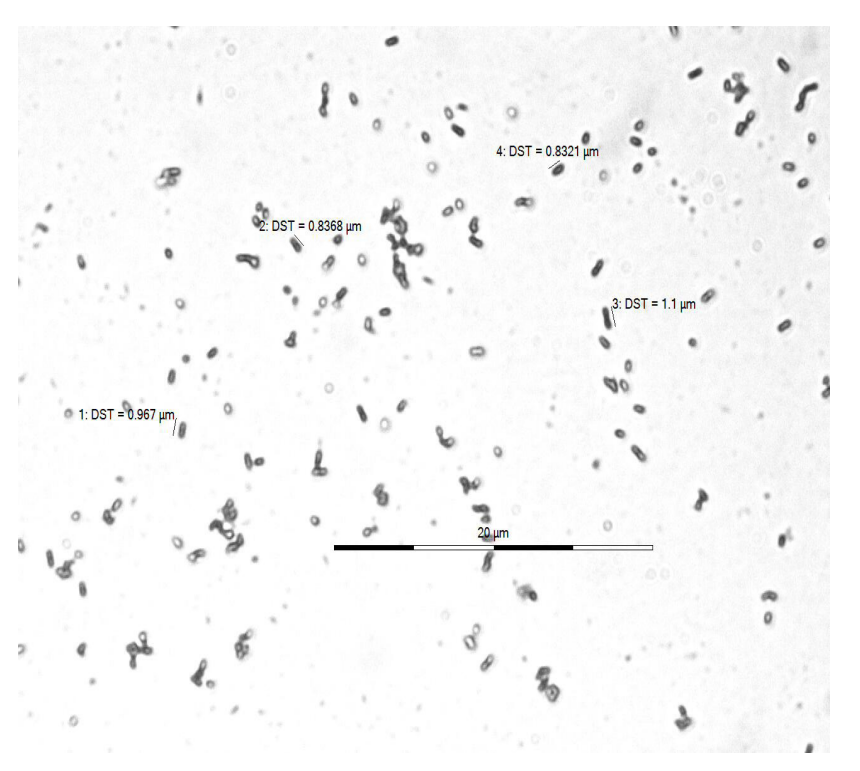

Fig. 8: Picture illustrates shape of cells after treatment; the unaffected cells appear either circular or cylindrical while the lysed cells form irregular shapes.

\section{CONCLUSIONS}

Upon enforcing local plasma jet effect inside the water bulk of different wastewater samples collected from Nizwa STP (at a location $2 \mathrm{~cm}$ from the water surface and around $1.5 \mathrm{~m}$ from the power inlet), the microorganism activity was totally reduced up to considerable limit in addition to other beneficial effects $\left(\mathrm{BOD}_{5}\right.$ and $\mathrm{COD}$ reduction). The presented technique has been proved competitive towards well known glow discharge generation techniques, shown in the literature, in terms of power consumption and environmental impacts. This treatment technique might become more fruitful upon subjecting the water bulk into more than one jet or rotating the water bulk during the treatment. Our future work will be dedicated to investigate the effect of applying cascade of jet plasma, in addition to exploring the microorganism types and their reactivity with the plasma treatment.

\section{CONFLICT OF INTEREST}

The authors declare no competing financial interest.

\section{ACKNOWLEDGMENT}

Wameath Abdul-Majeed thanks Mr. Ahmed Al-Abri, Ms. Aaisha Al Saidi and Ms. Maryam Al Hadidi for help in setting up and implementing the FJPT experiments. The authors thank Mr. Amjad Ali for help in producing the bacterial growth data.

\section{REFERENCES}

[1] Miclea M, Kunze K, Musa G, Franzke J, Niemax K (2001) The dielectric barrier discharge - a powerful microchip plasma for diode laser spectrometry. Spectrochim Acta B 56:37-43.

[2] Zhu Z, Chan G, Ray S, Zhang X, Hieftje G (2008) Microplasma source based on a dielectric barrier discharge for the determination of mercury by atomic emission spectrometry. Anal Chem 80:8622-8627.

[3] Pal U, Kumar M, Tyagi M, Meena B, Khatun H, Shamara A (2010) Discharge analysis and electrical modelling for the development of efficient dielectric barrier discharge. J Phys Conf Ser 208:012142.

[4] Zhu Z, Zhang S, Lv Y, Zhang X (2006) Atomization of hydride with a low-temperature, atmospheric pressure dielectric barrier discharge and its application to arsenic speciation with atomic absorption spectrometry. Anal Chem 78:865-872.

[5] He Y, Lv Y, Li Y, Tang H, Tang L, Wu X, Hou X (2007) Dielectric barrier discharge-induced chemiluminescence: potential application as GC detector. Anal Chem 79:4674-4680.

[6] Abdul-Majeed WS, Lozano Parada JH, Zimmerman WB (2011) Optimization of a miniaturized DBD plasma chip for mercury detection in water samples. Anal Bioanal Chem 401:2713-2722.

[7] Abdul-Majeed WS, Al-Thani GS, Al-Sabahi JN (2016) Application of Flying Jet Plasma for Production of Biodiesel Fuel from Wasted Vegetable 
Oil. Plasma Chem Plasma Process. 36 : 1517-1531.

[8] Wang X, Zhou M, Jin X (2012) Application of glow discharge plasma for wastewater treatment. Electrochimica Acta 83: 501- 512

[9] Jin X, Zhang H, Wang X, Zhou M (2012) An improved multianode contact glow discharge electrolysis reactor for dye discoloration Electrochimica Acta 59: 474-478.

[10] Gao J, Wang X, Hu Z, Deng H, Hou J, Lu X, Kang J (2003) Plasma degradation of dyes in water with contact glow discharge electrolysis. Water Research 37: 267-272.

[11] Gao J, Liu Y, Yang W, Pu L, Yu J, Lu Q (2003) Oxidative degradation of phenol in aqueous electrolyte induced by plasma from a direct glow discharge. Plasma Sources Sci. Technol. 12: 533-538.

[12] Amano R, Tezuka M (2006) Mineralization of alkylbenzenesulfonates in water by means of contact glow discharge electrolysis. Water Research 40: 1857 - 1863.

[13] Yan Z, Liu Y, Ren W, Yuan Z (2012) Investigation of liquid plasma catalysis on $\mathrm{Ti}$ electrodes for the decolorization of a brilliant red $\mathrm{B}$ solution. Journal of Electrostatics 70: 48-53.

[14] Wang L., Liu Y. (2012) Enhancement of Phenol Degradation by Electron Acceptors in Anodic Contact Glow Discharge Electrolysis. Plasma Chem Plasma Process 32:715-722.

[15] Liu Y, Jiang X (2005) Phenol Degradation by a Nonpulsed Diaphragm Glow Discharge in an Aqueous Solution. Environ. Sci. Technol. 39: 8512-8517.

[16] Jin XL, Xia Q, Wang XY, Yue JJ, Wei DB (2011) Inactivation of Microcystis aeruginosa with Contact Glow Discharge Electrolysis. Plasma Chem Plasma Process 31:697-705.

[17] Wang L., Jiang X (2008) Plasma-Induced Reduction of Chromium(VI) in an Aqueous Solution. Environ. Sci. Technol. 42: 8492-8497.

[18] Liu Y. (2009) Simultaneous oxidation of phenol and reduction of $\mathrm{Cr}(\mathrm{VI})$ induced by contact glow discharge electrolysis. Journal of Hazardous Materials 168: 992-996.

[19] Hase H, Harada K (2001) ESR detection of $\mathrm{OH}$ and $\mathrm{H}$ radicals generated by contact glow discharge in aqueous solutions. Viva Origino 29: 61-62.

[20] Liu Y, Sun B, Wang L, Wang D (2012) Characteristics of Light Emission and Radicals Formed by Contact Glow Discharge Electrolysis of an Aqueous Solution. Plasma Chem Plasma Process 32:359-368 [21] Srivastava Y, Jaiswal S, Singh OP, Gupta SK (2014) On the primary yield of radical products of anodic contact glow discharge electrolysis. Indian Journal of Chemistry 53A: 62-65.

[22] Wang L, Jiang X, Liu Y (2007) Efficient Degradation of Nitrobenzene Induced by Glow Discharge Plasma in Aqueous Solution. Plasma Chem Plasma Process 27: 504-515.

[23] Liu Y, Jiang X (2008) Plasma-induced Degradation of Chlorobenzene in Aqueous Solution. Plasma Chem Plasma Process 28:15-24.

[24] Gao J, Hu Z, Wang X, Hou J, Lu X, Kang J (2001) Oxidative degradation of acridine orange induced by plasma with contact glow discharge electrolysis. Thin Solid Films 390: 154-158.

[25] Abdul-Majeed WS, Karunakaran E, Biccs CA, Zimmerman WB (2015) Development of wastewater treatment system based on cascade dielectric barrier discharge plasma atomizers. Journal of Environmental Science and Health, Part A 50: 1249-1258.

[26] APHA. (1992). Standard methods for the examination of wate and wastewater. 18th ed. American Public Health Association, Washington, DC.

[27] Abdul-Majeed WS, AL-Handhali IM, AL-Yaquobi SH, Al-Riyami KO (2017) Application of Novel Polymeric Surface Remediation Technique Based on Flying Jet Plasma Torch. Ind. Eng. Chem. Res 56:11352-11358.

[28] Hegazi M, Gawad M (2016) Measuring and Evaluating the Performance of a Wastewater Treatment Plant, Proceedings of the World Congress on Civil, Structural, and Environmental Engineering, Paper No. AWSPT 111 (DOI: 10.11159/awspt16.111).

[29] Cai L, Zhang T (2013) Detecting Human Bacterial Pathogens in Wastewater Treatment Plants by a High-Throughput Shotgun Sequencing Technique. Environ. Sci. Technol. 47: 5433-5441.

[30] Cydzik-Kwiatkowska A, Zielin'ska M. (2016) Bacterial communities in full-scale wastewater treatment systems, World $\mathrm{J}$ Microbiol Biotechnol 32:66

[31] Wang X, Hu M, Xia Y et al. (2012) Pyrosequencing analysis of bacterial diversity in 14 wastewater treatment systems in China. Bioresour Technol 78(19):7042-7047. 